\title{
Learning about Vegetarian Diets in School: Curricular Representations of Food and Nutrients in Elementary Health Education
}

\author{
Clara Hanson \\ Department of Sociology, The George Washington University, Washington DC, USA \\ Email: clarah@gwu.edu \\ Received January $17^{\text {th }}$, 2012; revised February $18^{\text {th }}, 2012$; accepted March $1^{\text {st }}, 2012$
}

\begin{abstract}
This paper examines the way non-meat and plant based diets are discussed in four elementary curricula. The author used an open coding technique of grounded theory to understand the way food, nutrition and vegetarianism was discussed. The curricula relied heavily upon the USDA Food Pyramid and a related concept of "balance" for nutritional information. The curricula also discussed nutrition in terms of food and food groups, rather than in terms of nutrients. Although some of the curricula included information about the benefits of vegetarian diets, the high level of use of the Food Pyramid often overwhelmed the low level of information about vegetarianism.
\end{abstract}

Keywords: Vegetarianism; Veganism; Nutrition Curricula; Food Pyramid; Elementary Nutrition

\section{Introduction}

When I gave up meat the summer before my sophomore year of high school, my sister angrily tried to convince me not to. She said I might be dead in two years, definitely dead in five. It has been five years, and I am still here. I was a pescetarian for three years, a vegetarian for one, and I have been a vegan for almost two years. Over that time, I have been asked a lot of questions about how healthy my diet is, and what foods I eat. These questions usually indicate a lack of knowledge about basic nutrition, and often reveal misinformation about nutrition and diet. According to the American Dietetic Association, an appropriately planned vegetarian diet can provide adequate nutrition for children (ADA, 2010: p. 1246). If this is true, why was my sister convinced giving up meat would be fatal?

For this research project, I wanted to investigate whether or not students learned about vegetarianism in school. If they did, I wanted to investigate what information they were given, and how that information was framed. I assumed that if students were taught about vegetarianism, it would be within nutrition curricula. I conducted an exploratory study with four nutrition curricula. I used a grounded theory approach to code the dominant messages within the curricula. My major finding was a link between the word "balance" and the concept implied by the Food Pyramid that allowed the curriculums to imply the standard of the Food Pyramid without explicitly mentioning or showing it. Although the USDA recently changed its food guide model to the MyPlate guide, the Food Pyramid is still in circulation. Specifically, it was the focal point of three of the curricula I examined. The implications of the Food Pyramid in curricula can be understood through the work of Marion Nestle (2003). She explains that food lobbies, including the meat and dairy lobbies, have historically used their influence to alter the image of the Food Pyramid. She also explains that various food lobbies and food companies have influenced other curricula or published their own curriculum to reflect their own interests.
Most studies of nutrition curricula in the past ten years have been program analyses that attempted to evaluate whether specific curricula were effective at changing students' knowledge or behaviors. Many focused on fruit and vegetable outcomes. One 2002 study, for example, found that exposure to a gardenenhanced curriculum improved students' preferences for several vegetables (Morris \& Zidenberg, 2002: p. 92). Another evaluated students' ability to recognize fruits and vegetables. That study found that the majority of students defined "healthy eating" as something related to eating a "balanced" diet with high fruit and vegetable consumption (Edwards \& Hartwell, 2002: p. 373). Another study demonstrated the success of a program by showing that it increased students' knowledge of grains, fruits, and vegetables (Katz et al., 2010: p. 25). Although this evaluation offered many constructive ideas about the importance of multi-faceted interventions in nutrition education, it was primarily concerned with how much information about the Food Pyramid students retained. It did not consider whether learning about the Food Pyramid was a desirable objective. If the Food Pyramid is in fact flawed, so is this evaluation's definition of a successful program.

Other program evaluations that examined nutrition knowledge retention were limited by what the curriculum they evaluated contained. One study that focused on nutrition label literacy found that while their program increased knowledge, it did not significantly improve dietary patterns (McCaughtry et al., 2011: p. 282). Another study about general nutrition concluded that it had a positive effect on students because although the program did not improve students' understanding of vegetarian diets, it did increase students' understanding of the Food Pyramid, essential nutrients, and special dietary needs, which included the needs of astronauts (Moreno et al., 2004: p. 125). Some of the standards used to evaluate curricula focused very narrowly on particular interests, such as the evaluation of a swine-centered curriculum. The goal of this evaluation was to measure how effective the curriculum taught "subject matter 
relating to the pork industry, pork as a nutritious protein source, and the value of byproducts derived from pork production." (Wagler et al., 2008: p. 89) By this program's standards, a successful curriculum is measured by how much swine information students learn. The contrast between the various goals of these curricula and evaluations illustrates the variety of food ideologies present within curricula and within the greater nutrition debate.

The majority of the studies I found related to nutrition education were program evaluations of how effective a curriculum was at delivering its message. Many of the curricula under evaluation were narrowly tailored for specific industries. Their definitions of "success" vary from improvement in students' fruit and vegetable knowledge to the integration of knowledge about the pork industry. While evaluation studies are important, they do not problematize the manner in which nutrition information is framed or the implications of that framing. Few studies have analyzed nutrition curricula with the aim of revealing what these health education lessons indicate about larger societal priorities and ideologies. My study takes on this larger goal by investigating the way one topic, vegetarianism, is presented within four popular curricula. Investigating this particular topic sheds light on the place of vegetarianism in health education lessons specifically, and it also reveals the political and ideological work that is done when the lessons focus on "food groups" rather than "nutrients". Since nutrients comprise food this may seem like a neutral distinction, but food groups are, in fact, highly politicized demarcations that reflect the long-term, behind-the-scenes lobbying of many food industries. Normalizing the importance of "meat" in students' diets rather than "proteins", for example, both reflects these political and economic interests and socializes a generation of elementary school children to equate the two (protein = meat) and to think of vegetable, nut, and legume sources of protein as marginal, odd, and even dangerous.

\section{Data and Methods}

To conduct this analysis I initially tried to locate curricula by calling schools in the Rockville, Maryland area. I was told district was in the process of writing its own curriculum and could not release it yet, so I began to contact Maryland district offices instead. I had initial difficulty contacting the administrators in charge of nutrition curricula, which may be an important bit of data about the amount of transparency of nutrition education in the districts in this state. However, I was told by one administrator that the entire state was writing its own nutrition curriculum to be taught consistently throughout the state. Because the schools were in the process of a curriculum change, most were unable to share their current curriculum with me. The schools that were able to share the name of their former curricula had used curricula that were well above my research budget.

In order to bypass school districts, I independently located curriculum stores in Washington, DC, Maryland, and Virginia. I compared the inventory of three chains with multiple stores in the area: Education Outlet, Teacher's Mart, and Education Etc. If two or more of the stores sold the same curriculum, I saw it as an indicator of popularity. I decided to focus on curriculum designed for grades 4 - 6. I assumed that curricula designed for younger students might focus on more basic material, while nutrition education may not be a priority for students and teachers in higher grade levels. Because I used each store's online inventory, I did not consider whether the online store and the actual store had the same inventory. I found that all three stores sold Food, Nutrition \& Invention, Health Choices Grades 4 - 5, and Health, Nutrition and P.E. Grades 5 - 6. I found that two of the stores sold Healthy Eating \& Exercise. I ordered these four books because they were all designed for students in grades 4 6 . Because of their popularity and availability, it seemed feasible that they would be taught in schools across the DC metro area.

I analyzed these curricula as data using the open coding technique of grounded theory (Charmaz, 2006). I first read through each curriculum and recorded my initial reactions. Then, I coded each curriculum. To code, I made a spreadsheet using five categories for each code. The first two categories pertained to the location of the code-I recorded which book they were in and which page number. The next category was the type of code, be it an illustration, word, phrase, or concept. The fourth category contained a one-to-three-word description of the content of the code, such as "class". The final category was an extension of the fourth category, usually a more thorough description or, if the code was actual text, the sentence in which the code was contained. Throughout the process of coding, I noticed concepts consistently implied throughout the text. I paid closer attention to those codes, such as the concept of "balance." Because of the nature of my study, I tended to code sections that addressed vegetarianism more closely than sections that did not. When I finished coding, I printed the excel spreadsheet and highlighted the words that were used the most consistently. These words were Food Pyramid or food guide, balance or variety, milk, protein, any derivative of the word healthy, and vegetarian or vegan. For the purpose of this study, I defined a vegetarian as someone who abstained from animal product consumption to some extent. This includes pescetarians, who eat no animal flesh but fish; vegetarians, who eat no meat; vegans, who eat no meat or animal by-product, and any diet that falls in between these categories.

As a starting point for building my analysis of these concepts, I used the sensitizing concepts (Charmaz, 2003) gleaned from Marion Nestle's book Food Politics: How the food industry influences nutrition and health (2003). Nestle argues that the meat and dairy industries have influenced the dynamics of the Food Pyramid. In 1991 the Food Pyramid was redesigned and the meat and dairy groups were placed in an "eat less" category. At the time, the Physicians Committee for Responsible Medicine asked the United States Department of Agriculture (USDA) to replace food groups with vegetarian groups (Nestle, 2003: p. 56). In addition, nutritionists questioned whether the benefits of dairy outweighed the high levels of fat, hormones, and allergenic proteins of milk (Nestle, 2003: p. 79). Yet after the lobbying efforts of various meat and dairy lobbies, this version of the Food Pyramid was withdrawn. The USDA published a new version of the Pyramid that advocated for higher meat and dairy consumption than the original "Basic Four" one year later (Nestle, 2003: pp. 63-64). In other instances, the authors of nutritional standards have had direct ties to various factions of the food industry. For example, six of the 11 members of the 1998 nutritional guidelines committee had significant ties to the meat, egg, or dairy industry (Nestle, 2003: p. 73). The USDA is primarily responsible to the agricultural business, not eaters or consumers, and this is reflected in the nutritional guidance they provide via the Food Pyramid (Nestle, 2003: p. 51).

Nestle also highlights the ways food companies influence the information that is distributed within schools. Because parents 
tend to be too busy to watch what their children eat in school, she says, the responsibility of teaching children healthy dietary habits often rests on the school (Nestle, 2003: p. 196). However, commercial interests have infiltrated schools. Many firms specialize in planting commercial products in curricula and food guides. Some companies produce their own curriculum materials that play to their interests. For example, the Egg Board's curriculum minimizes the importance of cholesterol (Nestle, 2003: p. 190).

Nestle's work provides the political context necessary to inform my analysis of nutrition education curricula. I use this as background information to help me interpret the patterns apparent in four popular curricula. In the next section I describe how vegetarianism is presented in each of these curricula, along with an analysis of the apparent centrality of the Food Pyramid-and therefore of agricultural industry - in the lessons taught to many elementary school children.

\section{Health, Nutrition, and P.E.}

The first curriculum I coded was Health, Nutrition, and P.E., published in 2007. Its author, D. W. Skrabaneck, holds a Masters degree and has over twenty years of experience in teaching, writing and editing curricula. The curriculum is about general health and contains a 14-page section devoted to nutrition. The USDA Food Pyramid is the dominant source of nutritional guidance in the text. It frequently discusses nutrition in terms of foods rather than nutrients, and often linked certain foods to certain nutrients. Although this way of discussing nutrition may be more readily understood by students, it becomes problematic if certain sources of nutrients are privileged over others. Although the text attempts to discuss vegetarianism in a positive way, the lessons still present vegetarianism as a non-normative diet. The text also uses "balance" as a surrogate word for the concept of following the dietary guidelines of the Food Pyramid.

The Food Pyramid is a hierarchal structure that illustrates how many "servings" of each "food group" one should ingest per day. The food groups in the texts I examined tended to be grains, fruit, vegetables, dairy, meat and beans, and sugars and fats. Although the USDA has changed the names of the food groups and the structure of the guide under the new MyPlate guide, older versions of the Food Pyramid were still present in the curricula I examined. Health, Nutrition and P.E. emphasizes the Pyramid rather than other vehicles to understand nutrition. While the curriculum discusses the concept of nutrients such as proteins, minerals, and vitamins, this discussion appears on only one page of the curriculum. The Food Pyramid concept greatly overshadows the nutrient discussion as it is explicitly addressed on six pages of the 14-page curriculum (Skrabaneck, 2007: p. 3). Nutrients are not nearly as integrated in the lessons as the ongoing discussion of the Food Pyramid and food groups.

Not only does this curriculum discuss nutrition in terms of food groups and food sources more consistently than in terms of nutrients, it also tends to emphasize the value of other (nonmeat) animal products such as milk and eggs for their protein content. For example, in one activity two pages before the vegetarian section, students are asked to answer questions about the nutritional facts label of a box of cereal. The final question asks students to identify what the box suggests to increase protein content in the cereal. Although protein can be added to a breakfast in any number of ways, this label suggests adding whole milk (Skrabaneck, 2007: p. 75).

The text attempts to discuss vegetarianism positively, but it still treats vegetarianism as a non-normative diet. The section titled "Being a Vegetarian" begins with the sentence, "You've probably heard about vegetarians, but you may not know exactly what being a vegetarian means” (Skrabaneck, 2007: p. 77, boldface in the original). The text assumes that students have little to no previous knowledge of vegetarianism. The curriculum further asks why being a vegetarian might be a healthier choice than following a "traditional American diet". (Skrabaneck, 2007: p. 77) Although this suggests that being a vegetarian might be a healthy choice, it qualifies vegetarianism as a nontraditional, perhaps even non-American diet. By treating vegetarianism as a non-normative diet, the curriculum implies that it is a less viable diet for students than one centered on the Food Pyramid, and by extension on meat and dairy.

Health, Nutrition, and P.E. uses the concept of "balance" as a surrogate word for the Food Pyramid throughout the text. The curriculum first links balance to the Food Pyramid at the beginning of the text in its "Standards Chart." The book defines its educational standards by identifying the nutritional knowledge addressed by the curriculum. One standard that appears on five pages of the curriculum "explains how the Food Pyramid helps people obtain a balanced diet” (Skrabaneck, 2007: p. 4). In another section, a diagnostic test contains an explicit link between balance and the Food Pyramid. The first nutrition-related question reads: "The Food Pyramid shows the food groups and the amount of each group you need to eat for a diet" (Skrabaneck, 2007: p. 7). "Balance” and "vegetarian" are both listed as possible answers. The correct answer is balance. Not only is balance explicitly tied to the Food Pyramid, but balance is also portrayed as something that is not vegetarian. Because vegetarianism is not the correct answer, the reader might also assume that the Food Pyramid cannot be used to understand a vegetarian diet. This is problematic because the Food Pyramid is the curriculum's primary source of dietary guidance, and in this question it implies that the Food Pyramid does not have flexibility for non-normative diets.

The Food Pyramid is balanced and normative, while vegetarianism is not balanced and not normative. In what may be an attempt to normalize vegetarianism, this text does emphasize the value of some non-meat sources of protein throughout the text. However, those non-meat sources are still animal proteins: eggs and milk. The book links "healthy" vegetarianism to animal proteins with explicit statements such as, "Vegetarians who eat egg and milk products can easily get enough protein, an important part of a healthful diet” (Skrabaneck, 2007: p. 77). The curriculum also emphasizes the difficulties a vegetarian who does not consume animal proteins might have in consuming an adequate amount of protein (Skrabaneck, 2007: p. 77). Nestle (2003) might point out that many nutritional authorities have found that proper vegetarian diets often correlate with a number of health benefits, including lower blood pressure, lower rates of hypertension, and lower rates of type 2 diabetes (American Dietetic Association, 2009: p. 1266). However, this curriculum relies so heavily on the Food Pyramid that it cannot reconcile its advocacy of a diet rich in animal protein with advocacy of a diet devoid of animal protein within the same guide. The curriculum's reliance on the Food Pyramid is both explicit and implicit with the word "balance," and both of these con- 
cepts are in opposition to vegetarianism as a viable dietary option.

\section{Healthy Choices}

Like Health, Nutrition, and P.E., Healthy Choices is a health education curriculum that contains a nutrition section. It was published in 2006. (The author's name and credentials are not included in the book, and cannot be found on the publisher's website.) Also like the previous text, this curriculum uses the Food Pyramid as its main resource for nutritional information. This text even more explicitly links specific nutrients to specific food groups, particularly meat to protein and milk to calcium. This curriculum almost entirely neglects vegetarianism. It only mentions the diet once, in a negative context. "Balance" was used in the same way as in the previous curriculum, as a surrogate word for the Food Pyramid. This curriculum left little room for vegetarianism by emphasizing the authority of the Food Pyramid and animal sources of nutrients without addressing the benefits or drawbacks of a vegetarian diet.

This curriculum almost exclusively discusses diet in terms of the Food Pyramid. Although this text refers to it as the "Healthy Eating Guide," the first page of the nutrition section contains an image of the Food Pyramid (Didax, 2006: p. 23). \#The text discusses foods in terms of their food groups, and further ties food groups to certain nutrients. Protein is often tied to meat and dairy products, and calcium is almost exclusively tied to dairy products. Milk, yogurt, and cheese are said to provide calcium, protein, and energy (Diadax, 2006: p. 22). No other group provides the "nutrient" energy according to this text, although calories are present in every food and provide energy. According to the teacher's guide, the dairy group "is the best source of calcium for healthy bones and teeth.” (Diadax, 2006: p. 22) Dairy products are further tied to the benefits of calcium in a fill in the blank activity. In the activity, the only answer to the question "Which foods would help you build strong bones?" is dairy (Diadax, 2006: p. 27).

The link between nutrients and food sources does not stop at dairy. Animal sources of protein are also linked throughout the book. Although the book lists nuts and beans as sources of protein in some parts of the text, it also lists animal byproducts exclusively in other parts of the text. For example, one group of the Food Pyramid is defined as "meat, fish, poultry, eggs, nuts, legumes", and is linked to protein as well as other nutrients (Didax, 2006: p. 22). However, in another section of the book protein is defined as, "a common name given to the food group which contains meat, fish, eggs, cheese, milk, yogurt, etc," (Didax, 2006: p. 12). Students must apparently figure out for themselves what the "et cetera" might include.

This text almost completely ignored vegetarianism. The only time it mentioned vegetarianism is in the meat, fish, poultry, eggs, nuts, and legumes section of the teacher's guide. It reads, "iron supplements may be needed for vegetarians and those people who do not eat red meat” (Didax, 2006: p. 22). In this example, vegetarianism is portrayed as a diet that lacks nutrients rather than provides them. By not including an explanation about vegetarianism, the text does not even allow students to consider it.

On the first page of the nutrition section, "balance" is linked to the Food Pyramid under the heading "Healthy Eating”. A caption explains, "Everybody needs to have a well-balanced diet made up of a variety of foods from different food groups."
(Didax, 2006: p. 23) A chart on the next page lists the food groups under the heading “A Balanced Diet” (Didax, 2006: p. 25). These food groups include bread, cereal, rice, pasta, noodles; vegetables; fruit; meat, poultry, fish, legumes, eggs, nuts; milk, yogurt, cheese; fats, oils, sweets; and water. Interestingly, the image of the Food Pyramid itself is absent from this curriculum even while the word "balance" reminds students of its guidelines throughout the nutrition lessons.

In comparison to Healthy, Nutrition, and P.E., the use of the word "balance" in Healthy Choices is even more problematic for vegetarianism because this curriculum does not include any material that would allow students to consider it as a desirable or even viable option. The only time vegetarianism is brought up in the text is in the context of deficiency. By not offering a counter example of a healthy diet that does not follow the Food Pyramid, students are left to believe that a "balanced" diet planned according to the Food Pyramid's food-group-based standards is the only healthy diet possible. Further, by emphasizing animal sources of protein and calcium, the book implies that animals are the most suitable, and even the only sources of those nutrients.

\section{Healthy Eating \& Exercise}

The curriculum Healthy Eating \& Exercise, published in 2008, is almost exclusively devoted to nutrition. It was written by two women with impressive credentials: the first, Kerry Humes, attended Harvard University for her undergraduate degree and Northwestern University for her M.D. The second, Anne Davies, also attended Harvard University and then received her Master's degree from Oxford University. While the first author has experience as a medical doctor, the other has ten years of experience in children's publishing. Like the other curricula, this text uses the Food Pyramid as its dominant source of nutritional information, and it does link specific foods with specific nutrients. However, this curriculum attempts to break these links to a greater degree than the other two curricula. This curriculum portrays vegetarians positively to some degree, but it ultimately presents vegetarianism in a way that is at once simple and confusing. Although this curriculum didn't use the word balance in the same way the other two curriculums did, it did not need a surrogate word to incorporate the Food Pyramid throughout its text; the book's structure is based on the Food Pyramid, and therefore the Food Pyramid is present on every page. Of all the curricula, this one most clearly attempts to frame vegetarianism as a healthy diet.

The centrality of the Food Pyramid is apparent in three ways in this curriculum. First, the book intentionally structures its units based on the groups of the Food Pyramid (Davies and Humes, 2008: p. 1). The Food Pyramid is introduced at the beginning of the text with a large picture and a four-page unit about how to evaluate a diet based on the Pyramid (Davies and Humes, 2008: p. 3). The importance of the Food Pyramid is referenced in other units as well. For example, one activity within the grains and breakfast unit asks students to graph what percentage of the students in class are above the recommendations, are adhering to the recommendations, and are below the recommendations of one group of the Food Pyramid (Davies and Humes, 2008: p. 19).

While food and nutrients are linked in this curriculum, the text does not tie specific food groups to nutrients to the same degree as the others. Rather, it names a variety of foods from 
many groups that are a good source of a single nutrient. For example, when the book addresses calcium, it lists artichokes, broccoli, peas, kiwis, oranges, and blackberries as possible sources before milk, yogurt, and cheese (Davies \& Humes, 2008: p. 32). The teacher's guide at the beginning of the Meat, Beans, and Dairy section states that it is, "designed to help students start to think about getting protein from a variety of sources, not just red meat.” (Davies \& Humes, 2008: p. 59) The "Where's Your Protein From?” page allows students to calculate the actual amount of protein they need, and to chart how much protein they get from a variety of sources, including beans, dairy, grains, meat, fish, poultry, eggs, nuts, seeds, fruits, and vegetables (Davies \& Humes, 2008: p. 61).

Although this curriculum attempts to discuss a wider range of foods as a source of various nutrients than Health, Nurition, and P.E. and Healthy Choices, it sometimes still uses meat as a way to discuss protein and dairy as a way to discuss calcium. For example, the "What's up with Moo" page addresses lactose intolerance and alternative sources of calcium (Davies \& Humes, 2008: p. 63). However, dairy is still the focus of the page even when the curriculum attempts to differentiate between dairy and calcium. For example, the headline itself uses the word "moo," which implies dairy by evoking the noise of a cow. When the page lists non-dairy sources of calcium, they are discussed as sources of calcium that are not dairy rather than simply other sources of calcium. Another page lists dairy products as "excellent” sources of calcium, but says leafy green vegetables and beans are "'good' sources too". (Davies \& Humes, 2008: p. 64) One cup of skim milk contains 302 milligrams of calcium and 1/2 a cup of collard greens contains 179 (University of Michigan Health System, 2010). However, some studies report that milk can be high in saturated fat and other nutrients which weaken bones, undoing the work of calcium (Harvard School of Public Health, 2012). Although a serving of milk may be higher in calcium than a serving of many vegetables, one must consider the way all of the nutrients in milk as well as other foods interact with the body before they can be considered "excellent", "good”, or even undesirable sources of calcium.

The link between protein and animal foods are addressed in a similar manner. The curriculum discusses beans, nuts, and other plant sources as equals with animal sources in the meat, beans, and dairy section of the book. However, other sections of the book revert to using animal byproducts to discuss protein. For example, the grains and breakfast section suggests adding yogurt, eggs, or cheese to breakfast for additional protein without mentioning peanut butter or another plant based protein (Davies \& Humes, 2008: p. 10). In another activity, students are asked to imagine which three fruits and vegetables, one grain, and one dairy product they would bring to a deserted island. They are told there will be plenty of fish to catch for protein (Davies \& Humes, 2008: p. 34). This discourages students from thinking about the other foods they bring to the island as sources of protein.

Vegetarians are addressed in the meat, beans, and dairy section of the curriculum. Although three pages of the text are devoted to vegetarianism, none of them gives a coherent definition of what a vegetarian is or explains in depth why someone might consider becoming one. I would argue that because the vast majority of Americans are raised eating animal foods regularly, they do not regularly consider other types of diets. Because the Food Pyramid is structured to perpetuate this kind of diet, it creates a loop that perpetuates the consumption of foods already frequently consumed by Americans. Although this is the only text to use the word "vegan", it uses vegetarian and vegan interchangeably and does not clearly distinguish between the two terms. The section also assumes students have a certain degree of knowledge about vegetarians. It suggests that students may not be aware that some religions are associated with vegetarianism, and prompts the teacher to explain it (Davies \& Humes, 2008: p. 59). This implies that students should already be familiar with the animal rights, environmental, and health reasons for being a vegetarian, and so these reasons are not addressed. This section also encourages students to think of vegetarianism as a meal choice rather than as a lifestyle choice. It says, "You don't have to be a vegetarian to enjoy vegetarian dinners.” (Davies \& Humes, 2008: p. 68). Although this approach may encourage students who aren't willing or able to make a complete dietary lifestyle change to try vegetarianism to some degree, it does not make the vegetarian diet as accessible to students as much as it could. The curriculum also discusses vegetarian meals on two pages of the curriculum, and the vegetarian lifestyle on only one. Although this text appears to intend to discuss vegetarianism positively, the way it does so is in fact somewhat problematic.

Unlike the other curricula, this book did not use the word "balance" consistently throughout its text. It used the word balance occasionally, but not to imply the structure of the Food Pyramid. The function of the word balance in the other texts was to maintain the presence of the Food Pyramid throughout the text. Although this text does not use the word balance as the other texts do, almost any given page contains the ideology of the Food Pyramid. Although this text does not imply the Food Pyramid with a word, it does use another mechanism to maintain a presence of the Food Pyramid throughout the book.

This curriculum discusses food and nutrients in a way that supports both meat and non-meat based diets as healthy. By naming a variety of foods that contain a certain nutrient rather than more tightly associating a food group with a certain nutriaent, the book made the discussion of vegetarianism as a healthy diet possible before the text reached its vegetarian section. However, the text failed to make a clear statement about vegetarianism in its vegetarian section. The potential this book has for positive vegetarian nutrition education is ultimately overshadowed by the Food Pyramid, which was used to structure the book.

\section{Food Nutrition \& Invention}

The final text I analyzed was Food Nutrition \& Invention. This curriculum differs from the other books because it teaches English and writing skills along with nutrition. It was originally published in Canada in 1996 before it was revised and entered the American market in 2007. Because the text is used in both Canada and the US - two countries with different food guidesno images of either food guide or discussion of specific servings and guidelines appear in the text. The curriculum suggests using "your country's food guide” to teach lessons (Southall \& Wearing, 2007: p. 12). Although the actual Food Pyramid is not present in the text, the curriculum still organizes its text around the food groups. For example, the book uses food groups to discuss the ways different types of foods are produced. Despite the appearance of certain concepts of the Food Pyramid, the curriculum discusses vegetarianism in a positive way. Not only does this curriculum discuss the food pyramid, nutrients, and 
vegetarianism in a way that was different from the other curricula, but it also encourages students to consider the ethics of food production. The discussion of food production was completely absent from the other three curricula, perhaps because of the ramifications such a public discussion could potentially have for certain factions of the food industry.

Food Nutrition \& Invention sometimes links food groups to nutrients, but it also provides additional information about how foods are manufactured. For example, the Meat and Alter- natives section explains that most eggs come from hens kept in cages on large battery farms (Southall \& Wearing, 2007: p. 14). Information about the nature of food production encourages students to think about food in a variety of ways, not simply as a source of nutrients. Even so, the text does link food groups to nutrients early on. In the preface to a section that describes each food group, for instance, calcium is linked to dairy, and these links are present throughout the rest of this section.

This curriculum did not discuss vegetarianism in depth, but did discuss vegetarianism in a relatively supportive manner when it was addressed. The term is first mentioned at the beginning of the book as part of a classroom activity. The teacher is asked to, "explain the term vegetarian to your students and discuss possible reasons for people making this decision, as well as the nutritional value of alternatives to meat" (Southall \& Wearing, 2007: p. 5). The motives and benefits for being vegetarian are not included in this text, so it is impossible to know what the curriculum intends teachers to say. However, vegetarianism is still portrayed positively. The word vegetarian is also used in a fill-in-the-blank activity. Once solved, the sentence reads, "A person who chooses not to eat meat is called a vegetarian. A vegetarian may get protein from those foods as well as milk and eggs" (Southall \& Wearing, 2007: p. 14). The other foods listed include beans and nuts. However, within the sentence, vegetarianism is linked directly to milk and egg consumption. The final time vegetarianism is used in this text is in a section in which students are asked to define a variety of essential words, including calorie, nutrient, famine, protein, fiber, and vitamin (Southall \& Wearing, 2007: p. 63). The book indicates that vegetarianism is important by positioning it with other important words.

\section{Analysis and Implications}

One of the primary findings of this analysis is that the Food Pyramid has a very substantial role in the structure and concept of three of the four curricula I examined. While vegetarianism was present in every curriculum, and was portrayed positively in three, the presence of the Food Pyramid overwhelmed the presence of vegetarianism overall. The American Dietetic Association, American Heart Asssociation, Mayo Foundation for Medical Education and Research, and even the USDA itself say that vegetarian diets can meet nutrient requirements (American Heart Association, 2011; Mayo Clinic, 2010; United States Department of Agriculture 2011). I do not argue that a vegetarian-dominant curriculum should replace the curricula I examined. Rather, I argue that the structure of the curricula I examined tended to favor a single type of diet based on the Food Pyramid rather than allowing students to consider a wide array of healthy dietary choices, including vegetarianism. If both a vegetarian diet and a diet based on the Food Pyramid can provide adequate nutrition, there must be a reason that does not have anything to do with nutrition that allows the Food Pyramid to be so dominant in nutrition curricula. This difference in diet portrayal can be understood through Nestle's theory in Food Politics.

The Food Pyramid is a government-sponsored dietetic model, which gives it a great deal of perceived authority in Americans' dietary practices. The United States Department of Agriculture constructs the Food Pyramid (and now the MyPlate guide). As Nestle explains, the authority of the USDA to construct a national dietary model is problematic because the USDA is responsible to the agriculture industry, not to nutritionists (Nestle, 2003: p. 51). Nestle demonstrates that various lobbies, including dairy and meat lobbies, used their influence to pressure the USDA to construct a dietary model more sympathetic to their products (Nestle, 2003: pp. 61-65). For example, the 2000 Guidelines use the word "saturated fat" rather than "animal fat" to appease the industries that would be affected by the Guidelines' recommendation to limit intake of "saturated" or "animal” fat (Nestle, 2003: pp. 77-78). As another product of the USDA, the Food Pyramid to an extent reflects the interests of the food industries with the most clout rather than the latest scientific knowledge about diet. If nutrition curricula publish the Food Pyramid and rely heavily on it for their own dietary recommendations, nutrition curricula also reflect the interests of the food lobbies that changed the Pyramid.

When the curricula I analyzed do incorporate discussions of vegetarianism, they try to fit vegetarianism within the guidelines of the Food Pyramid by stressing the importance getting enough protein and other nutrients from animal foods such as eggs and milk. Only one curriculum, Healthy Eating \& Exercise, makes a clear and consistent effort to link calcium with non-dairy foods. The tendency to portray milk as the best, and sometimes only, source of calcium can be traced to some of the nation's most prestigious groups. For example, the Institute of Medicine recommended in 2007 that milk, including flavored milk, should be sold throughout schools to improve children's calcium consumption (Yaktine, Okita et al., 2007: p. 4). While it is difficult to question the most prestigious groups in American medicine, it is also problematic to obscure nutritional facts: milk is not the only source of calcium, and animal foods are not the only sources of protein.

The meat, dairy, and other agriculture industries have disproportionate influence in creating the Food Pyramid, and these guidelines represent what Americans consider a normative and ideal diet. By attempting to fit vegetarianism within the guidelines of the Food Pyramid, the curricula in this analysis transform the structure of a vegetarian diet to one that includes a high amount of animal foods. In doing so, the lobbies that influence the structure of the Food Pyramid, namely the meat and dairy lobbies, also influence the way people who might be considered least likely to consume their products - vegetarians eat. Although the meat and dairy industries may not have directly influenced the curricula I examined, the curricula's contents still served their interests.

The more often the Food Pyramid is used in nutrition curricula, the more the companies whose interests it reflects benefit. By linking the word "balance" to the Food Pyramid, the ideology of the Pyramid is even more widely dispersed. This is particularly problematic considering how frequently "balance" is used to discuss nutrition inside and outside curricula. By linking the word balance to the Food Pyramid, these curricula shape students' understanding of the meaning of "balance" within discussions of nutrition as a diet as an idea related to the Food Pyramid and food groups regardless of the context of the word. 
Although the interests of those involved with the meat, dairy, and egg industries are perpetuated by the Food Pyramid and "balance", their influence is obscured by the legitimacy of the less controversial entities that disseminate nutritional messages, such as the USDA and the Institute of Medicine. Although certain information and language about diet may seem legitimate and a-political, especially considering the authority and legitimacy of its creators, it actually furthers the interests of certain factions of the food industry. This type of information and language does its job best, in fact, because they obscure the political interests of the industries they ultimately serve.

One striking element of these texts as a whole is their lack of a clear explanation of vegetarianism, as well as their conflation of veganism and vegetarianism. Three of the curricula address vegetarianism briefly, and they all conflate veganism and vegetarianism in some way. Health, Nutrition, and P.E. discusses vegetarians and vegetarians who do not eat animal byproducts, but it emphasizes the ease of maintaining a diet that included animal byproducts and health of vegetarians who consume animal byproducts (Skrabanek, 2007: p. 77). Healthy Eating \& Exercise uses the words "vegetarianism" and "veganism" interchangeably in its vegan section, and the curriculum does not include information that distinguishes vegetarians and vegans from each other (Davies \& Humes, 2008: p. 59). Food Nutrition \& Invention defines a vegetarian as "a person who eats only vegetable foods and refrains from eating meat" (Southall \& Wearing, 2007: p. 96). A person who only eats vegetable foods is a vegan, while a person who refrains from eating meat is a vegetarian. Yet this different is ignored. This conflation could be avoided in each text if the authors included clearer information about the difference between the two diets and what the various rationales for participating in them are.

The texts largely shy away from discussing the ethics and politics at play in abstaining from certain food sources. Healthy Eating \& Exercise, for example, chooses to discuss religions that practice vegetarianism rather than discuss the health, environmental, or ethical reasons to abstain from met or animal byproducts. The fact that the curricula are unwilling to address vegetarian politics stands in sharp contrast to their implicit adoption of the politics of the Food Pyramid. The structure of the curriculum is influenced by the politics of food lobbies, and the book shies away from discussing politics that might be unsupportive of that influence. This tendency to avoid what appears political in the first three curricula stands in stark contrast to the final curriculum. Not only does the final curriculum rely on nutrition structures other than the Food Pyramid to discuss diet, but it also addresses the food industry and ethics to a degree. For example, it explains that most eggs come from battery farms and the growing trend of fish farms (Southall \& Wearing, 2007: p. 14). The structure of this curriculum suggests that food ethics can be successfully and meaningfully incorporated into nutrition education.

After completing my research, I believe elementary school nutritional curricula would benefit from using a dietary model other than the Food Pyramid. They could perhaps focus on nutrients instead of food groups. At the very least, curricula could benefit from discussing the Food Pyramid as only one possibility to maintain a healthy diet, and could explain other viable alternative diets as equally valid options. De-emphasizing the Food Pyramid would enable students to consider other types of diets more seriously. Because I focused on vegetarianism, I often had to overlook other parts of the curricula. An additional study might examine the way other topics such as organic food, locally grown food, food allergies, and food production are covered.

Despite their portrayal in this set of curricula, vegetarians do have many sources of protein and other nutrients to choose from and this diet appears to have many health benefits (American Dietetic Association, 2009: p. 1266). Yet in these curricula, vegetarianism is consistently placed within the proteinfocused sections. This implies that getting protein is the biggest hurdle for vegetarians, and encourages readers to think about vegetarianism in terms of what vegetarians do not eat rather than what they do. Vegetarianism could be moved to a different section of the curricula and be addressed in a different, more positive context. For example, vegetarianism could be moved to the fruit and vegetables section of these texts and discussed as a pro-plant diet, rather than as an anti-meat diet.

After coding and analyzing curricula sold throughout the DC Metropolitan Area, I am not surprised that my sister thought I would quickly die on a vegetarian diet. If this set of curricula is any indication of the quality of information American children receive about the health and practice of vegetarianism, my sister's worries are quite understandable. The curricula are structured almost exclusively on the Food Pyramid and the related code word "balance", and their food-based (rather than nutrition-based) approaches obscure the full information students could have access to. Quite simply, vegetarianism is largely incompatible with the structure of a Food Pyramid-based curriculum even though it is a nutritionally viable diet. It is understandable for teachers to rely on the nutrition guidelines the government produces, but Marion Nestle makes the convincing point that these guidelines are not neutral or apolitical. Rather, they are a reflection of industry interests. A curriculum that follows the guidelines of the Food Pyramid better suits the economic interests of certain factions of the food industry rather than the nutrition and health interests of the public. Simply, what is good for business is not always what is good for your body. Corporate lobbies, then, rather than dispassionate scientists and nutritionists are guiding children's nutrition education. Analyzing these curricula's portrayal of vegetarianism supports Nestle's work by showing the way corporate interests may be obscured by apparently legitimate and uninterested producers. However, corporate interests are actually amplified according to the frequency, exclusivity, and scale the Food Pyramid is used to teach new generations about diet and health.

\section{Acknowledgements}

The author would like to thank Ivy Ken for her support, critique, and insight. Her guidance made all the difference in this paper's direction and content.

\section{REFERENCES}

American Dietetic Association. (2010). Position of the American Dietetic Association: Local support for nutrition integrity in schools. Journal of the American Dietetic Association, 110, 1244-1254. doi:10.1016/j.jada.2010.06.014

American Dietetic Association. (2009). Position of the American Dietetic Association: Vegetarian Diets. Journal of the American Dietetic Association, 109, 1266-1282. doi:10.1016/j.jada.2009.05.027

American Heart Association. (2011). Vegetarian diets. URL (last checked 14 December 2011)

http:/www.heart.org/HEARTORG/GettingHealthy/NutritionCenter/ 


\section{HANSON}

Vegetarian-Diets_UCM_306032_Article.jsp\#

Charmaz, K. (2003). Grounded theory: Objectivist and constructivist methods. In N. K. Denzin, \& Y. S. Lincoln (Eds.), Strategies for qualitative inquiry (2nd ed., pp. 249-291). Thousand Oaks, CA: Sage.

Charmaz, K. (2006). Constructing grounded theory. A practical guide through qualitative analysis. London: Sage.

Davies, A., \& Humes, K. (2008). Healthy eating \& exercise. Quincy, IL: Mark Twain Media.

Didax Educational Resources. (2006). Healthy choices. Rowley, MA: World Teachers Press.

Edwards, J. S. A., \& Hartwell, H. H. (2002). Fruit and vegetablesAttitudes and knowledge of primary school children. Journal of Human Nutrition and Dietetics, 15, 365-374.

doi:10.1046/j.1365-277X.2002.00386.X

Harvard School of Public Health. (2012). Calcium and milk. URL (last checked 13 February 2012).

http://www.hsph.harvard.edu/nutritionsource/what-should-you-eat/ca lcium-and-milk/

Katz, D., Katz, C., Treu, J., Reynolds, J., Njike, V., Walker, J. et al., (2010). Teaching healthful food choices to elementary school students and their parents: The nutrition detectives program. Journal of School Health, 81, 21-28. doi:10.1111/j.1746-1561.2010.00553.x

Mayo Clinic Staff. (2010). Vegetarian diet: How to get the best nutrition. Mayo Foundation for Medical Education and Research. URL (last checked 14 December 2011).

http://www.mayoclinic.com/health/vegetarian-diet/HQ01596

McCaughtry, N., Fahlman, M., Martin, J., \& Shen, B. (2011). Influences of constructivist-orientated nutrition education on urban middle school students' nutrition knowledge, self-efficacy, and behaviors. American Journal of Health Education, 42, 276-285.

Moreno, N. et al. (2004). An approach to improving science knowledge about energy balance and nutrition among elementary- and middleschool students. Cell Biology Education, 3, 122-130. doi:10.1187/cbe.03-08-0008

Morris, J., \& Zidenberg, S. (2002). Garden-enhanced nutrition curriculum improves fourth-grade school children's knowledge of nutrition and preferences for some vegetables. Journal of the American Dietetic Association, 102, 91-93. doi:10.1016/S0002-8223(02)90027-1

Nestle, M. (2003). Food politics: How the food industry influences nutrition and health. Berkeley, CA: University of California Press.

Skrabanek, D. W. (2007). Health, nutrition, and P.E. Orlando, FL: Harcourt Archieve Inc.

Southall, M., \& Wearing, J. (2007). Food: Nutrition \& invention. Niagara Falls, NY: On the Mark Press.

United States Department of Agriculture. (2011). Vegetarian diets. URL (last checked 14 December 2011). http://www.choosemyplate.gov/tipsresources/vegetarian_diets.html

University of Michigan Health System. (2010). Calcium and Vitamin D. URL (last checked 13 February 2012).

http://www.med.umich.edu/1libr/guides/calcium.htm

Wagler, S. et al. (2008). Classroom evaluation of an elementary educational swine curriculum: There's a pig in my classroom. Journal of Agricultural Education, 49, 87-98. doi:10.5032/jae.2008.03087

Yaktine, A., Okita, J., Akhlaghi, A., Vorosmarti, A., \& Del Valle, H. (2007). Nutrition standards for foods in schools: Leading the way toward healthier youth. National Academies Press, Cambridge, 1-8. 